\title{
Does Hyperthermic Intraperitoneal Perfusion Affect the Outcome After Cytoreductive Surgery?
}

\section{Kireeva GS ${ }^{1}$, Gafton $\mathrm{GI}^{2}$, Senchik KY², Petrov VG ${ }^{2}$, Semiglazov VV², Guseynov KD ${ }^{3}$, Bespalov VG4 Belyaeva $\mathrm{OA}^{4}$ and Belyaev $\mathrm{AM}^{2}$}

${ }^{1}$ Department of Carcinogenesis and Aging, N.N. Petrov Research Institute of Oncology, Russian Ministry of Health, Saint-Petersburg, Russia

${ }^{2}$ Department of General Oncology, N.N. Petrov Research Institute of Oncology, Saint-Petersburg, Russia

${ }^{3}$ Department of Gynecologic Oncology, N.N. Petrov Research Institute of Oncology, Saint-Petersburg, Russia

${ }^{4}$ Department of Cancer Chemoprevention and Oncopharmacology, N.N. Petrov Research Institute of Oncology, Saint-Petersburg, Russia

*Corresponding author: Kireeva GS, Researcher in the Department of Carcinogenesis and Aging, N.N. Petrov Research Institute of Oncology, Russian Ministry of Health, Saint-Petersburg, Russia, Tel: +7-981-831-73-06; E-mail: galinakireyeva@mail.ru

Rec date: December 21, 2016; Acc date: December 28, 2016; Pub date: December 30, 2016

Citation: Kireeva GS, Gafton GI, Senchik KY, et al. Does Hyperthermic Intraperitoneal Perfusion Affect the Outcome After Cytoreductive Surgery? J Clin Gastroenterol Hepatol 2016, 1: 1.

\section{Abstract}

Outcomes of hyperthermic intraperitoneal chemoperfusion (HIPEC) added to cytoreductive surgery were studied in experimental and clinical settings. 32 female Wistar rats with peritoneal carcinomatosis were used in the experiment. Rats were randomized into 4 groups (8 rats each): I - control group; II - cytoreduction; III - hyperthermic intraperitoneal perfusion without drugs (HIPEP); IV - cytoreduction + HIPEP.

In clinical part of the study 7 patients with pseudomixoma peritonei underwent cytoreductive surgery with hyperthermic intraperitoneal chemoperfusion (HIPEC). As the result of the experiment post-operative morbidity taken as post-operative complications and the restoration of body weight after surgery was more severe in animals who received combination of cytoreductive surgery + HIPEP compared to animals who received the surgery or HIPEP alone.

The median survival of rats in the control group, cytoreduction, HIPEP and cytoreduction + HIPEP were 8.5, $25(p=0.007$ compared to control), $23.5 \quad(p=0.003$ compared to control) and $19.5(p=0.034$ compared to control) days respectively. In clinical part of the study post-operative complications were registered in 2 patients, one of them died on day 12 after the surgery.

The pattern of complications was mainly determined by the volume of cytoreductive surgery. Two more patients died due to the tumor progression. Four patients are currently alive with follow-up 4-28 months. Cytoreductive surgery combined with HIPEC should be performed in patients with pseudomyxoma peritonei to increase their survival time. Morbidity from this approach has to be reduced by formulating the strategy of optimal cytoreduction in the studies including larger number of patients.

\section{Keywords:}

Pseudomyxoma peritonei; Peritoneal carcinomatosis; Cytoreductive surgery; Hyperthermic intraperitoneal chemoperfusion (HIPEC)

\section{Introduction}

Peritoneal surface malignancies are associated with high rate of morbidity and mortality. It remains one of the most difficult conditions to manage in cancer patients. A reasonable progress in this field has been made with introduction of aggressive treatment strategy combining cytoreductive surgery and hyperthermic intraperitoneal chemoperfusion (HIPEC). This strategy has been known and utilized for over 40 years now in selected patients with peritoneal carcinomatosis from colorectal, ovarian and gastric cancer as well as with peritoneal mesothelioma and pseudomyxoma peritonei. For example, even 20 years ago patients with pseudomyxoma peritonei were suggested only interval debulking to improve their quality of life but without a chance for a long-term survival [1]. Suggesting radical peritonectomy aimed at removing as much macroscopic disease as possible followed by HIPEC to eliminate microscopic and residual disease resulted in significant improvement of outcomes with 5- and 10-years survival being $40-87$ and $50 \%$ to $74 \%$ respectively [2-10]. However, combination cytoreductive surgery + HIPEC are considered as a treatment modality with high rate of postoperative morbidity and mortality by some authors [11]. Moreover, there is a consistent opinion that cytoreductive surgery alone is a safer option and adding HIPEC increases the risk of severe complications $[4,6]$. This hasn't been proved in any clinical study but it often makes surgeons to refuse from 
performing HIPEC in those patients who could benefit from this treatment.

We performed experimental study in rats with peritoneal carcinomatosis aiming to explore association between hyperthermic perfusion (alone and in combination with cytoreductive surgery) and post-operative morbidity, and also, we analyzed clinical results of performing cytoreductive surgery with HIPEC in patients with pseudomyxoma peritonei.

\section{Materials and Methods}

\section{Experimental study}

Maintenance and care of all experimental animals were carried out according to the ethical principles established by the European convention for the protection of vertebrate animals, used for experimental and other scientific purposes (accepted in Strasbourg 18.03.1986 and confirmed in Strasbourg 15.06.2006), and approved by Local ethical committee of N.N. Petrov Research Institute of Oncology.

To simulate peritoneal carcinomatosis we used tumor cells of ascitic ovarian cancer which has been characterized elsewhere [12]. Ascites from a rat with ovarian cancer was taken, diluted with saline (1:4) and injected intraperitoneally (IP) to healthy rats at a number of $1 \times 107$ cells per rat. 32 female Wistar rats weighing 210-250 g (3-4 months of age) were used in the experiment. After ovarian cancer transplantation all rats were randomized into 4 groups ( 8 rats each): I - control group, sham operation with $0.5 \mathrm{ml}$ of normal saline IP without perfusion; II - cytoreduction; III hyperthermic IP perfusion group with saline (HIPEP), in which the peritoneal cavity of the rats was perfused with heated normal saline; IV - cytoreduction + HIPEP. In 48 hours after ovarian cancer transplantation animals were anesthetized with $60 \mathrm{mg} / \mathrm{kg}$, i.p. thiopental sodium (Joint-Stock Company Kurgan Medicines and Products Synthesis, Russia) and placed on a heating table. Heart rate and respiratory rate were monitored during surgery. Prior to surgery rats were given ketoprofen 5

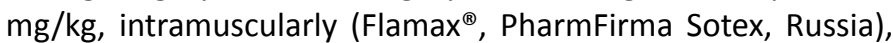
for analgesia and $5 \mathrm{ml}$ of saline subcutaneously for prophylaxis of rehydration. Laparotomy with injection of $0.5 \mathrm{ml}$ of normal saline was performed in rats in the group I. Cytoreductive surgery including standard omentectomy was performed in animals in the group II and IV. For HIPEP in groups III and IV an inflow catheter and digital thermometer to monitor intraabdominal temperature were inserted into the right upper abdomen and an outflow catheter was inserted into the left lower abdomen. Catheters were attached to the perfusion circuit. The circuit consisted of plastic tubing connecting the peritoneal cavity to a peristaltic pump "Mars" (Russian State Scientific Center for Robotics and Technical Cybernetics) and thermostatic precision bath LB-200 (LOIP, Russia) heated up to $44.5^{\circ} \mathrm{C}$ to $45.0^{\circ} \mathrm{C}$. During perfusion the circuit was filled with $250 \mathrm{ml}$ of $0.9 \%$ sodium chloride. Intra-abdominal and rectal temperatures were monitored using digital CheckTemp thermometers (Hanna, Germany). Optimal parameters of the perfusion established in model validating experiments were: pump speed - 10-15 $\mathrm{ml} / \mathrm{min}$, time of the perfusion $-45 \mathrm{~min}$, intraabdominal temperature during the perfusion $-40.5^{\circ} \mathrm{C}$ to $41.5^{\circ} \mathrm{C}$ [13]. At the end of perfusion, the solution was evacuated and the abdomen was irrigated with $200 \mathrm{ml}$ of saline for $20 \mathrm{~min}$, then catheters and thermometers were taken out, and the abdominal wall and skin were closed in two layers using the sterile sutural absorbable polyglactin for the fascia and non-absorbable polyester sterile sutural material for the skin. In 24 hours after the operation animals received Ceftriaxon (Medaxon ${ }^{\circledR}$, "Medokemi Ltd.", Cyprus) 93 mg/kg, intramuscularly and Hemobalance (Nature Vet, Australia) 0.1 $\mathrm{ml}$, subcutaneously.

The primary end point was median survival which was calculated as time from inoculation of ovarian cancer until the animal death. Secondary end point was reduction in body weight after the surgery.

\section{Clinical study}

All procedures performed in studies involving human participants were in accordance with the ethical standards of the institutional and national research committee and with the 1964 Helsinki declaration and its later amendments or comparable ethical standards. Informed consent was obtained from all individual participants included in the study.

Cytoreductive surgery followed by HIPEC was performed in 7 patients with pseudomyxoma peritonei in the Department of general oncology in N.N. Petrov Research Institute of Oncology of the Russian Ministry of Health in the period from 2006 to 2015. Patient's characteristics are presented in Table 1. Mean age of the patients was $43.7 \pm 10.2$ years; mean body weight $80.7 \pm 18.8 \mathrm{~kg}$. Three patients had pseudomyxoma peritonei of appendiceal origin, two patients had pseudomyxoma peritonei of ovarian origin and three other patients had pseudomyxoma peritonei of unknown origin. Three out of seven patients presented with the recurrence of the disease.

Table 1 Patients characteristics.

\begin{tabular}{|c|l|l|l|l|}
\hline No. & Gender & Age & Weight, $\mathbf{k g}$ & Diagnosis \\
\hline 1 & Male & 36 & 103 & adenocarcinoma of the appendix with the formation of PMP \\
\hline 2 & Female & 33 & 55 & mucinous cystadenoma of the ovary with the formation of PMP, recurrence \\
\hline 3 & Male & 39 & 88 & mucinous adenocarcinoma of the appendix (PMP) T4bN0M1a \\
\hline
\end{tabular}




\begin{tabular}{|l|l|l|l|l|}
\hline 4 & Female & 59 & 100 & PMP, recurrence \\
\hline 5 & Male & 39 & 68 & PMP \\
\hline 6 & Female & 43 & 63 & $\begin{array}{l}\text { mucinous carcinoma of the appendix (PMP), recurrence with intraperitoneal } \\
\text { dissemination }\end{array}$ \\
\hline 7 & Female & 57 & 88 & PMP \\
\hline \multicolumn{2}{|l}{ PMP - pseudomyxoma peritonei }
\end{tabular}

All patients underwent cytoreductive surgery aimed to following HIPEC (Table 2). Peritonectomy was performed in eliminate as much macroscopic tumors as possible with the five out of seven patients.

Table 2 Characteristics of cytoreductive surgeries and HIPEC in patients with pseudomyxoma peritonei.

\begin{tabular}{|c|c|c|c|c|}
\hline \multirow{2}{*}{ No. } & \multirow{2}{*}{ Cytoreductive surgery } & \multicolumn{3}{|c|}{ Hyperthermic intraperitoneal chemoperfusion } \\
\hline & & Drug & IP temperature & Time \\
\hline 1 & $\begin{array}{l}\text { Hemicolectomy, splenectomy, resection of the tail of the } \\
\text { pancreas }\end{array}$ & MMC $40 \mathrm{mg}$ & $41.0-42.0^{\circ} \mathrm{C}$ & $90 \mathrm{~min}$ \\
\hline 2 & $\begin{array}{l}\text { Transverse colectomy, resection of the cecum, resection of } \\
\text { the ascending colon, ileocecal resection, low anterior } \\
\text { resection, pelvic peritonectomy }\end{array}$ & MMC $40 \mathrm{mg}$ & $41.0-42.0^{\circ} \mathrm{C}$ & $90 \mathrm{~min}$ \\
\hline 3 & Extended right hemicolectomy, partial peritonectomy & Cisplatin $150 \mathrm{mg}$ & $42.5-43.5^{\circ} \mathrm{C}$ & $60 \mathrm{~min}$ \\
\hline 4 & $\begin{array}{l}\text { Removal of the recurrent tumor nodules, peritonectomy, } \\
\text { omentectomy, right hemicolectomy }\end{array}$ & Cisplatin 200 mg & $42.5-43.5^{\circ} \mathrm{C}$ & $60 \mathrm{~min}$ \\
\hline 5 & Splenectomy, omentectomy, subtotal peritonectomy & Cisplatin 250 mg & $41.0-42.0^{\circ} \mathrm{C}$ & $90 \mathrm{~min}$ \\
\hline 6 & $\begin{array}{l}\text { Subtotal peritonectomy, splenectomy, two-sided diaphragm } \\
\text { resection, liver decortication }\end{array}$ & Cisplatin $250 \mathrm{mg}$ & $41.0-42.0^{\circ} \mathrm{C}$ & $90 \mathrm{~min}$ \\
\hline \multirow[b]{2}{*}{7} & Omentectomy & Cisplatin $100 \mathrm{mg}$ & $42.5-43.5^{\circ} \mathrm{C}$ & $60 \mathrm{~min}$ \\
\hline & $\begin{array}{l}\text { Splenectomy, resection of the tail of the pancreas, small } \\
\text { bowel resection }\end{array}$ & $\begin{array}{l}\text { Cisplatin } 100 \mathrm{mg} \\
+ \\
\text { MMC } 20 \mathrm{mg}\end{array}$ & $42.5-43.5^{\circ} \mathrm{C}$ & $60 \mathrm{~min}$ \\
\hline
\end{tabular}

The equipment for HIPEC was basically the same as for the experimental study the only difference being the addition of microporous filter with a pore diameter of 30 microns (Maquet, Germany). After cytoreductive surgery 2 inflow drains were inserted into the upper abdomen (subdiaphragmatic space) and 2 outflow drains were inserted into the lower abdomen. The abdomen was sutured in layers and the drains were connected to the closed perfusion circuit. The inflow and the outflow drains had thermo probes to monitor the temperature of the perfusion. The volume of the perfusate (normal saline) was 4-4.5 liters. HIPEC was performed with cisplatin (100-250 mg), mitomycin C (40 mg) or with the combination cisplatin $100 \mathrm{mg}+$ mitomycin C 20 $\mathrm{mg}$. The drugs were infused into the perfusion circuit after the temperature of the perfusate reached the target values (Table 2). Infusion of the drugs was considered as the start of HIPEC.

Statistical analysis was performed using programs GraphPad $^{\circledR}$ Prism 6, SPSS $^{\circledR}$ Statistics version 17.0. The statistical analysis of survival carried out with Lilliefors test, median life spans - Mann-Whitney $U$ test, survival curves Mantel-Cox test (Log-rank test) test. $\mathrm{P}<0.05$ was considered statistically significant.

\section{Results}

\section{Experimental study}

48-hour period from the moment of ovarian cancer inoculation to the moment of treatment was proved to be enough for peritoneal tumor nodules to develop. Histological study of the peritoneal tumor nodes proved them to be ovarian cancer metastases (Figure 1). Autopsy of the animals from the control group demonstrated carcinomatosis of visceral and parietal peritoneum, greater and lesser omentum, mesentery, metastatic affection of lymph nodes in the abdominal cavity. 

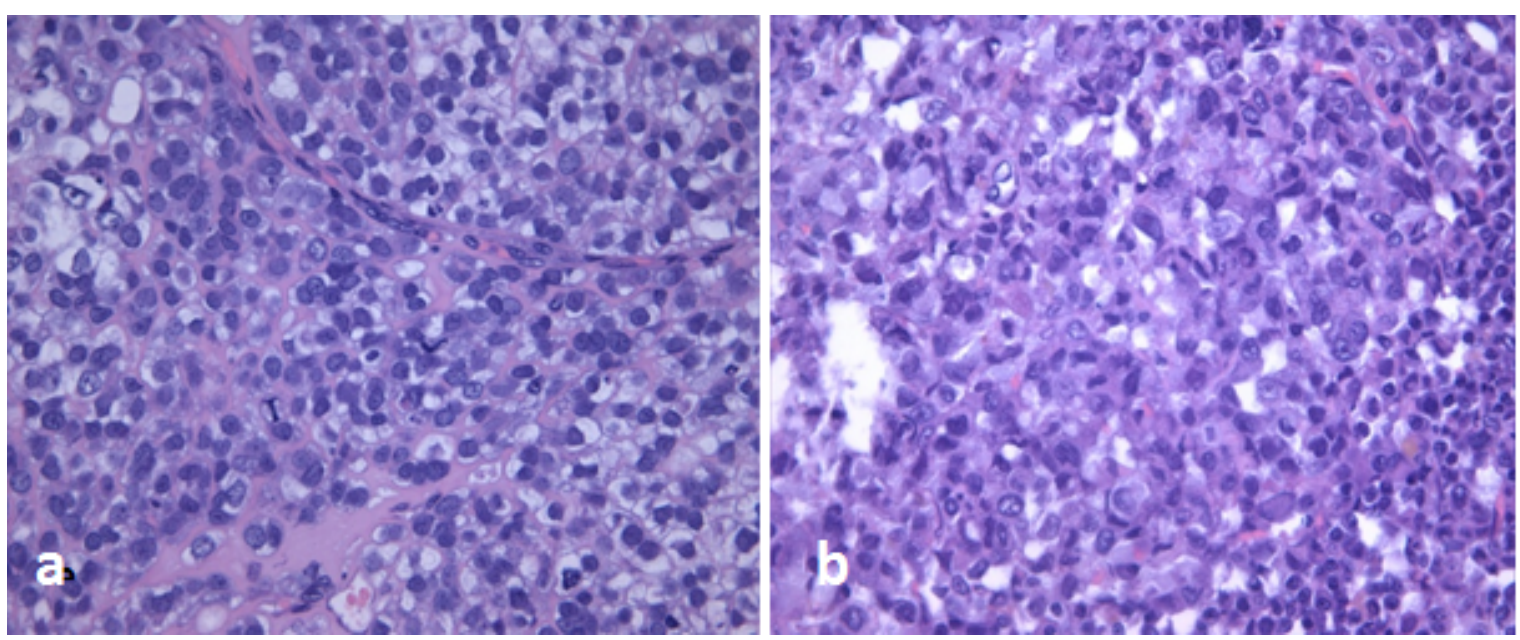

Figure 1 Metastasis of the poorly differentiated epithelial ovarian cancer to the parietal peritoneum (a), mesenteric lymph nodes (b), histology preparation, hematoxylin / eosin, $\times 400$.

All animals in groups II, III and IV survived the tumor incubation time ( 48 hours), the operation and immediate postoperative period. The highest post-operative morbidity was registered in group IV; however it didn't differ significantly from groups II and III (Table 3). Mesenteric necrosis in group II was found at autopsy in one animal. All other complications were cured.

The trends were similar in groups II and III: the minimal relative body weight was registered on day $3194 \%$ and $96 \%$ respectively) and after that there was a consistent increase in this parameter. However body weight loss was more significant and it restored slower in rats after cytoreduction compared to HIPEP alone. The most significant changes in relative body weight were registered in group IV where animals received combination of cytoreductive surgery with HIPEP. The lowest value if this parameter was $89 \%$ on day 6 after the surgery and it completely restored back to $100 \%$ only by the day 15 (Figure 2). The difference in relative body weight on day 6 between groups II and IV was significant $(p=0.043)$. At other time points differences between groups didn't reach statistical significance.

Table 3 Post-operative complications in rats with ovarian cancer.

\begin{tabular}{|c|c|c|c|c|c|}
\hline Groups & Pneumonia & $\begin{array}{l}\text { Mesenteric } \\
\text { ischemia and } \\
\text { bowel necrosis }\end{array}$ & Peritonitis & $\begin{array}{l}\text { Intra-abdominal } \\
\text { bleeding }\end{array}$ & $\begin{array}{l}\text { Total number of rats with post- } \\
\text { operative complications }\end{array}$ \\
\hline I. Control & 0 & 0 & 0 & 0 & 0 \\
\hline $\begin{array}{l}\text { II. Cytoreduction } \\
(n=8)\end{array}$ & 0 & 1 & 1 & 1 & $\begin{array}{l}3 \\
p=0.1 \text { (vs. control) }\end{array}$ \\
\hline $\begin{array}{l}\text { HIPEP } \\
(n=8)\end{array}$ & 1 & 0 & 0 & 1 & $\begin{array}{l}2 \\
p=0.094 \text { (vs. control) } \\
p=0.524 \text { (vs. cytoreduction) }\end{array}$ \\
\hline $\begin{array}{l}\text { IV. Cytoreduction + } \\
\text { HIPEP }(n=8)\end{array}$ & 2 & 0 & 1 & 0 & $\begin{array}{l}3 \\
p=0.098 \text { (vs. control) } \\
p=0.312 \text { (vs. cytoreduction) } \\
p=0.112 \text { (vs. HIPEP) }\end{array}$ \\
\hline
\end{tabular}




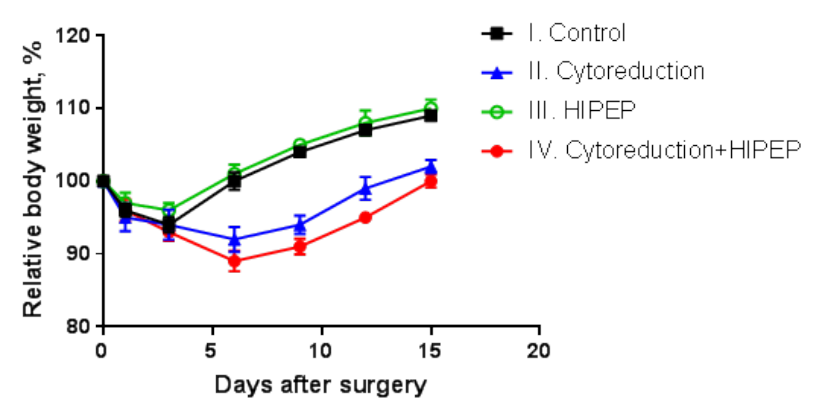

Figure $\mathbf{2}$ Changes in relative body weight of rats with ovarian cancer after the surgery.

The median survival of rats in the control group, cytoreduction, HIPEP and cytoreduction + HIPEP were 8.5 (95\% confidence interval (Cl) 6.8-12.4), 25 (95\% Cl 12.6-29.4), 23.5 (95\% Cl 13.6-33.9) and 19.5 (95\% Cl 9.2-32.9) days respectively (Figure 3).

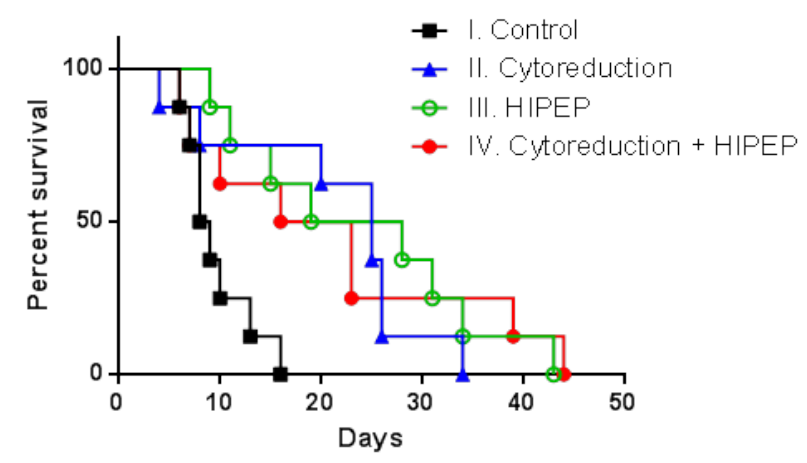

Figure 3 Survival curves of rats with ovarian cancer after the surgery.

Table 4 Outcomes of patients with pseudomyxoma peritonei.
All three treatment modalities significantly increased survival of rats with ovarian cancer compared to the control group. The $p$-values when compared control group vs. cytoreduction, HIPEP and cytoreduction + HIPEP were 0.007, 0.003 and 0.034 respectively. However adding HIPEP to cytoreduction didn't improve the outcomes compared to cytoreduction or HIPEP alone. The $\mathrm{p}$-values when compared cytoreduction + HIPEP vs cytoreduction and HIPEP were 0.875 and 0.970 respectively.

\section{Clinical study}

From 2006 to 2015 eight HIPEC procedures were performed in seven patients with pseudomyxoma peritonei in the Department of general oncology in N.N. Petrov Research Institute of Oncology of the Russian Ministry of Health. In patient 2 with recurrent pseudomyxoma peritonei HIPEC was repeated in one year after the previous surgery that was made in another clinic. Therefore in two out of seven cases (patients 2 and 7) two courses of HIPEC were performed.

In two cases (patients 2 and 5) severe post-operative complications developed which were related mainly to the volume of the surgical intervention (Table 4). To manage the complications in patient 2 relaparotomy was performed twice with suturing the stomach body defect, separation of colocolonic anastomosis due to its failure, single-barrel colostomy formation. This patient was discharged in satisfactory condition on day 21 after the surgery.

One patient (patient 5) died in early post-operative period. Acute perforation of gastric wall with gastrointestinal bleeding happened on the day 9 after the surgery which required atypical gastrectomy. After that even with intensive care patient's condition remained poor with negative dynamics due to progressive multiple organ failure because of the severe abdominal sepsis. The patient died on the 12 post-operative days. Other 6 patients were discharged in satisfactory condition on days 14-21 after the surgery.

\begin{tabular}{|c|c|c|c|}
\hline No. & Complications & Adjuvant chemotherapy & Long-term outcome \\
\hline \multirow{4}{*}{1} & \multirow{4}{*}{-} & FOLFOX 2 courses & \multirow{4}{*}{ Alive for 4 months } \\
\hline & & leucovorin 400 mg/m², & \\
\hline & & $5-\mathrm{FU} 400 \mathrm{mg} / \mathrm{m}^{2}$ & \\
\hline & & $5-\mathrm{FU} 2400 \mathrm{mg} / \mathrm{m}^{2}$ & \\
\hline 2 & $\begin{array}{l}\text { the stomach body defect, colo-colonic anastomosis } \\
\text { failure, } \\
\text { pelvioperitonitis, left sided hydrothorax, right sided } \\
\text { hydronephrosis grade II }\end{array}$ & - & Alive for 15 months \\
\hline \multirow{4}{*}{3} & \multirow{4}{*}{-} & FOLFOX6 6 cycles & \multirow{4}{*}{ Alive for 24 months } \\
\hline & & oxaliplatin $100 \mathrm{mg} / \mathrm{m}^{2}$, & \\
\hline & & leucovorin $400 \mathrm{mg} / \mathrm{m}^{2}$, & \\
\hline & & 5-FU 400 mg/m², & \\
\hline
\end{tabular}




\begin{tabular}{|c|c|c|c|}
\hline & & $5-\mathrm{FU} 2400 \mathrm{mg} / \mathrm{m}^{2}$ & \\
\hline & & "DeGramont" 3 cycles & \\
\hline & & leucovorin $400 \mathrm{mg} / \mathrm{m}^{2}$ & \\
\hline & & $5-\mathrm{FU} 400 \mathrm{mg} / \mathrm{m}^{2}$ & \\
\hline & & $5-F U 2400 \mathrm{mg} / \mathrm{m}^{2}$ & \\
\hline 4 & - & - & Alive for 28 months \\
\hline 5 & $\begin{array}{l}\text { Acute pancreatitis, acute perforation of gastric wall, } \\
\text { gastrointestinal bleeding. Progressive multiple organ } \\
\text { failure because of the severe abdominal sepsis }\end{array}$ & - & Died on the 12 post-operative day \\
\hline \multirow{10}{*}{6} & \multirow{10}{*}{-} & FOLFOX 6 cycles (first line): & \multirow{10}{*}{ Died in 14 months after the surgery } \\
\hline & & oxaliplatin $85 \mathrm{mg} / \mathrm{m}^{2}$, & \\
\hline & & leucovorin $200 \mathrm{mg} / \mathrm{m}^{2}$, & \\
\hline & & $5-\mathrm{FU} 400 \mathrm{mg} / \mathrm{m}^{2}$ & \\
\hline & & $5-\mathrm{FU} 600 \mathrm{mg} / \mathrm{m}^{2}$ & \\
\hline & & FOLFIRI 7 cycles (second line): & \\
\hline & & irinotecan $180 \mathrm{mg} / \mathrm{m}^{2}$ & \\
\hline & & leucovorin $200 \mathrm{mg} / \mathrm{m}^{2}$, & \\
\hline & & $5-\mathrm{FU} 400 \mathrm{mg} / \mathrm{m}^{2}$ & \\
\hline & & 5 -FU $600 \mathrm{mg} / \mathrm{m}^{2}$ & \\
\hline 7 & - & - & Died in 12 months after the surgery \\
\hline
\end{tabular}

Three of the discharged patients received adjuvant systemic chemotherapy (Table 4). FOLFOX was chosen as adjuvant chemotherapy for these patients based on the experience of oncologists in N.N. Petrov Research Institute of Oncology as it showed to improve outcomes of patients with unresectable or recurrent pseudomyxoma peritonei. Patient 6 progressed after the first line of chemotherapy with metastases in lungs, liver, abdominal lymph nodes, pleura and peritoneum. The following 7 cycles of chemotherapy failed to improve the prognosis and the patient died in 3.5 months after finishing the treatment with total 14 months alive after the surgery. Patient 7 developed recurrence of pseudomyxoma complicated with ascites in 12 months after the second surgery with HIPEC. Cytoreductive surgery was performed including resection of the tumor of anterior abdominal wall; subtotal gastrectomy; small bowel resection; transverse colon resection; resection of the tail of the pancreas; wedge resection of the liver; cholecystectomy. HIPEC was not added to the surgery. Disseminated intravascular coagulation developed on the second post-operative day. Urgent relaparotomy was performed with plugging the subhepatic space and the spleen with a tampon. However, the patient 7 died on day 3 after the cytoreductive surgery because of the bleeding and hemorrhagic shock.

The remaining 4 patients (patients 1, 2, 3 and 4) are currently alive with no signs of tumor progression even though two of them had recurrence of pseudomyxoma peritonei at the time of admission. Only 3 out of 7 patients in our study received adjuvant chemotherapy, and 1 patient had tumor progression with chemotherapy. From this data, we can't say if chemotherapy influenced on the outcomes of patients after cytoreductive surgery and HIPEC (Figure 4).

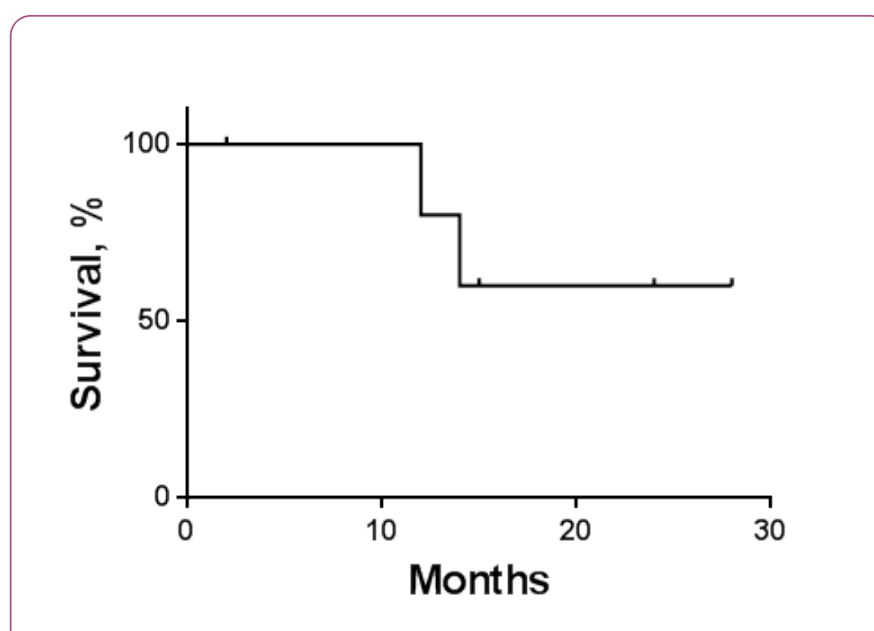

Figure 4 Survival of patients with pseudomyxoma peritonei after the cytoreductive surgery and HIPEC.

\section{Discussion}

Combination cytoreductive surgery + HIPEC remain the treatment option with high rate of post-operative morbidity 
(up to $54 \%$ ) and mortality (up to $11 \%$ ) [1,4-6,8]. The most common post-operative complications are anastomotic leakage, gastrointestinal and pancreatic fistulas, pneumonia, thromboembolism, and abdominal abscess [14]. Many authors agree that the rate and severity of post-operative complications are due to the type and volume of cytoreductive surgery and do not depend on the adding of HIPEC $[15,16]$. From the other point of view HIPEC could increase the risk of anastomotic leakage and/or spontaneous perforation [17]. The efficacy of HIPEC is probably less debatable question especially in patients with pseudomyxoma peritonei [18]. Twenty years ago, these patients were considered incurable receiving suboptimal cytoreduction with no chances for long-term survival [1]. Sugarbaker et al. introduced new technique with cytoreduction aiming to remove as much macroscopic tumor nodules as possible followed by HIPEC. This treatment modality provides 5- and 10-year survival of patients with pseudomyxoma peritonei up to $72 \%$ and $55 \%$ respectively $[1,19]$. In patients with peritoneal carcinomatosis from ovarian cancer the role HIPEC is not so obvious. In certain clinical studies, median progressive free and overall survival of these patients reach 57 [20] and 69 months respectively [21]. However, some studies do not show any advantages of HIPEC in terms of survival outcomes [22].

In experimental part of this study we performed HIPEP without antitumor drugs alone and in combination with cytoreductive surgery in female rats with peritoneal carcinomatosis from ovarian cancer. Post-operative morbidity taken as post-operative complications and the restoration of body weight after surgery was more severe in animals who received combination of cytoreductive surgery + HIPEP (group IV) compared to animals who received the surgery or HIPEP alone (groups II and III respectively). The efficacy of these three treatment modalities was comparable without any statistically significant difference in animals' survival. This is probably due to the fact that we didn't use chemotherapeutic agent (e.g. cisplatin) during perfusion focusing on the use of hyperthermia alone in order to evaluate its impact on postoperative course after the hyperthermic perfusion without systemic toxicity and side effects caused by a drug.

In clinical part of the study we analyzed treatment outcomes of 7 patients with pseudomyxoma peritonei after cytoreductive surgery with HIPEC. According to the published data this combination is especially effective in cases of pseudomyxoma of appendecial origin [18]. According to the large multicenter register containing data about 2298 patients with pseudomyxoma peritonei median survival of these patients after the combined treatment is 196 months and $59 \%$ of all patients live 15 years and longer [23]. In Russian literature, there has been only one study exploring effects of HIPEC in patients with pseudomyxoma peritonei by Abdullaev et al. [24]. From 2007 to 2010 authors performed cytoreductive surgery with HIPEC in 10 patients. Intraperitoneal recurrence was registered in one case in 8 months after peritonectomy with HIPEC. Other 9 patients were alive for 7-27 months with no signs of progression by 2010 . These survival results are similar to those in our study, although Abdullaev et al. didn't have patients with recurrent disease. Also authors didn't describe the post-operative morbidity in patients.

In our study, severe post-operative complications were registered in two patients (patients 2 and 5). Patient 2 had defect of the anterior gastric wall and leakage in colo-colonic anastomosis while patient 5 had gastric wall perforation and gastrointestinal bleeding. These complications are most likely to be the result of the massive surgery (Table 4). One patient (patient 7) died after the third cytoreductive surgery which unlike previous two was not followed by HIPEC. Also the volume of the third surgery significantly exceeded the volume of the previous surgeries. The survival outcomes of treatment could be considered as satisfactory. Two patients who were operated for the recurrence of pseudomyxoma peritonei (patients 2 and 4) have been alive for 15 and 28 months respectively, and two patients with primary tumor (patients 1 and 3 ) have been alive for 24 and 4 months respectively.

\section{Conclusion}

In experimental settings, we showed that adding hyperthermic intraperitoneal perfusion without chemotherapeutic drugs to cytoreductive surgery doesn't increase the risk of post-operative complications but impair the post-operative recovery of rats with peritoneal carcinomatosis from ovarian cancer. There was no difference in survival in animals receiving cytoreductive surgery + hyperthermic intraperitoneal perfusion and animals receiving cytoreduction or perfusion alone. In patients with pseudomyxoma peritonei it was shown that HIPEC improve survival outcomes of these patients. Post-operative morbidity of combined treatment is mainly due to the type and volume of cytoreductive surgery rather than due to adding of HIPEC. To determine absolute indications for HIPEC in patients with pseudomyxoma peritonei and to include this technology into the standards of care for cancer patients further research in larger number of patients is required to establish the reliable advantages of the procedure, its risks, and possible ways to minimize these risks.

\section{Declaration of Interest Statement}

The authors report no declarations of interest.

\section{References}

1. Chua TC, Moran BJ, Sugarbaker PH, Levine EA, Glehen O, et al. (2012) Early and long-term outcome data of patients with pseudomyxoma peritonei from appendiceal origin treated by a strategy of cytoreductive surgery and hyperthermic intraperitoneal chemotherapy. J Clin Oncol 30: 2449-2456.

2. Baratti D, Kusamura S, Nonaka D, Langer M, Andreola S, et al. (2008) Pseudomyxoma peritonei: Clinical pathological and biological prognostic factors in patients treated with cytoreductive surgery and hyperthermic intraperitoneal chemotherapy (HIPEC). Ann Surg Oncol 15: 526-534.

3. Chua TC, Yan TD, Smigielski ME, Zhu KJ, Ng KM, et al. (2009) Long-term survival in patients with pseudomyxoma peritonei treated with cytoreductive surgery and perioperative 
intraperitoneal chemotherapy: 10 years of experience from a single institution. Ann Surg Oncol 16: 1903-1911.

4. Stewart JHT, Shen P, Russell GB, Bradley RF, Hundley JC, et al. (2006) Appendiceal neoplasms with peritoneal dissemination: outcomes after cytoreductive surgery and intraperitoneal hyperthermic chemotherapy. Ann Surg Oncol 13: 624-634.

5. Bevan KE, Mohammed F, Moran BJ (2010) Pseudomyxoma peritonei. World J Gastrointest Oncol 2: 44-50.

6. Bespalov VG, Kireeva GS, Belyaeva OA, Kalinin OE, Senchik KY, et al. (2016) Both heat and new chemotherapeutic drug dioxadet in hyperthermic intraperitoneal chemoperfusion improved survival in rat ovarian cancer model. J Surg Oncol 113: 438-442.

7. Haslinger MA, Francescutti V, Attwood K (2013) Contemporary analysis of morbidity and outcomes in cytoreduction/ hyperthermic intraperitoneal chemoperfusion. Cancer Med 2: 334-342.

8. Gori J, Castano R, Toziano M, Häbich D, Staringer J, et al. (2005) Intraperitoneal hyperthermic chemotherapy in ovarian cancer. Int J Gynecol Cancer 15: 233-239.

9. Di Giorgio A, Naticchioni E, Biacchi D, Sibio S, Accarpio F, et al. (2008) Cytoreductive surgery (peritonectomy procedures) combined with hyperthermic intraperitoneal chemotherapy (HIPEC) in the treatment of diffuse peritoneal carcinomatosis from ovarian cancer. Cancer 113: 315-325.

10. Abdullaev AG, Gorbunova VA, Ter-Ovanesov MD (2010) Cytoreductive interventions combined with hyperthermic intraperitoneal chemoperfusion in patients with pseudomyxoma. Tumors of the Female Reproductive System 4: 98-102.

11. Hamilton T, Lanuke K, Mack LA, Temple WJ (2011) Temple longterm follow-up in the treatment of peritoneal carcinomatosis. Am J Surg 201: 650-654.

12. Halabi HEl, Gushchin V, Francis J, Athas N, Macdonald R, et al. (2012) The role of cytoreductive surgery and heated intraperitoneal chemotherapy (CRS/HIPEC) in patients with highgrade appendiceal carcinoma and extensive peritoneal carcinomatosis. Ann Surg Oncol 19: 110-114.

13. Elias D, Gilly F, Quenet F, Bereder JM, Sidéris L, et al. (2010) Pseudomyxoma peritonei: A French multicentric study of 301 patients treated with cytoreductive surgery and intraperitoneal chemotherapy. Eur J Surg Oncol 36: 456-462.

14. SGonzalez-Moreno S, Sugarbaker PH (2004) Right hemicolectomy does not confer a survival advantage in patients with mucinous carcinoma of the appendix and peritoneal seeding. Br J Surg 91: 304-311.

15. Spiliotis JD, Rogdakis A, Vaxevanidou A, Datsis A, Zacharis G, et al. (2009) Morbidity and mortality of cytoreductive surgery and hyperthermic intraperitoneal chemotherapy in the management of peritoneal carcinomatosis. Journal of BUON 14: 259-264.

16. Helm CW, Richard SD, Pan J, Bartlett D, Goodman MD, et al. (2010) HIPEC in ovarian cancer: first report of HYPER-O registry. Int J Gynecol Cancer 20: 61-69.

17. Austin F, Mavanur A, Sathaiah M, Steel J, Lenzner D, et al. (2012) Aggressive management of peritoneal carcinomatosis from mucinous appendiceal neoplasms. Ann Surg Oncol 19: 13861393.

18. Honore C, Caruso F, Dartiques P, Benhaim L, Chirica M, et al. (2015) Strategies for preventing pseudomyxoma peritonei after resection of a mucinous neoplasm of the appendix. Anticancer Res 35: 4943-4947.

19. Bespalov VG, Kireeva GS, Belyaeva OA, Senchik KY, Stukov AN, et al. (2016) Experimental study of antitumour activity and effects on leukocyte count of intraperitoneal administration and hyperthermic intraperitoneal chemoperfusion (HIPEC) with dioxadet in a rat model of ovarian cancer. J Chemother 28: 203209.

20. Mohamed F, Cecil T, Moran B, Sugarbaker P (2011) A new standard of care for the management of peritoneal surface malignancy. Curr Oncol 18: 84-96.

21. Abu-Rustum NR, Barakat RR, Levine DA (2013) Atlas of procedures in gynecologic oncology, (3rd edn) CRC Press, New York.

22. Youssef H, Newman C, Chandrakumaran K, Mohamed F, Cecil TD, et al. (2011) Operative findings, early complications, and longterm survival in 456 patients with pseudomyxoma peritonei syndrome of appendiceal origin. Dis Colon Rectum 54: 293-299.

23. Smeenk RM, Verwaal VJ, Antonini N, Zoetmulder FA (2007) Survival analysis of pseudomyxoma peritonei patients treated by cytoreductive surgery and hyperthermic intraperitoneal chemotherapy. Ann Surg 245: 104-109.

24. Sugarbaker PH (1994) Pseudomyxoma peritonei: A cancer whose biology is characterized by a redistribution phenomenon. Ann Surg 219: 109-111. 